Check for updates

London, UK

Cite this as: $B M J 2021 ; 372: m 4829$ http://dx.doi.org/10.1136/bmj.m4829 Published: 11 January 2021

\section{Why I ... collaborate with European colleagues}

\section{GP trainee Stuart Holmes talks to Helen Jones about his work with teams of GPs from across Europe}

\section{Helen Jones}

"I've been actively involved in WONCA Europe since my first year of GP training and I am evangelical about it," says Stuart Holmes. "Nothing nourishes your resilience like getting to know international colleagues who share your enthusiasm for your specialty."

He has found that being part of an international organisation has improved his work life. "It's helped me develop my sense of vocation as a GP," Holmes says. "There's sometimes negativity about being a GP in the UK-even from GPs-and engaging with the European GP community is the perfect antidote. Each time I go to an event I feel re-energised.”

It was during a night shift that he first decided to get involved with WONCA-the World Organisation of National Colleges, Academies, and Academic Associations of General Practitioners and Family Physicians, or World Organisation of Family Doctors.

"I had some downtime and thought there must be some kind of international group for GP trainees," he says. "I came across a link on the Royal College of General Practitioners' website for WONCA and then saw that they were advertising for an exchange, so I applied.”

Holmes spent three days being hosted by Portuguese GPs in Porto, observing their practice, and then attended a WONCA conference. "Exchanges with peers allow you to see first hand how your specialty can be done in a different context," he says.

WONCA conferences and workshops also provide insights into areas beyond participants' normal experiences. "For example, I've been to a workshop about physician assisted suicide which was run by GPs from the Netherlands. It's the sort of thing that you would never learn about in the UK."

WONCA Europe is made up of different networks covering a range of matters, enabling members to get involved in a variety of projects. "The scientific content at these meetings tends to be delivered by the participants, so it's a great opportunity to collaborate with colleagues and submit abstracts," he says.

"Being a member of WONCA isn't just about work. The pan-European mix brings a richness and new ways of thinking that you don't get at UK only events."

\section{How to get involved}

- Anyone who is a member of the Royal College of General Practitioners is a member of WONCA

- The level of participation in WONCA and its young doctors' movement, the Vasca da Gama Movement (VdGM) varies. "Some people may just go to the annual conference once a year, while others might join networks to collaborate with colleagues from different parts of Europe or get involved in projects in their own specific area of interest," Holmes says

- To find out more about WONCA and VdGM visit: www.woncaeurope.org and www.vdgm.eu 